\title{
COMUNICAÇÃO PLURAL: ALTERIDADE E SOCIABILIDADE ${ }^{1}$
}

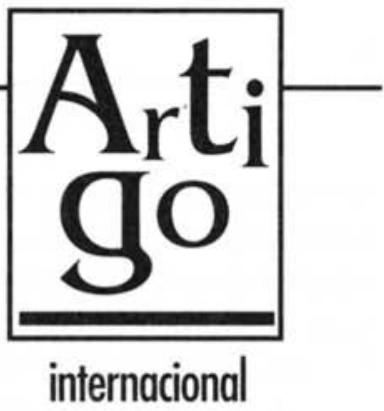

\section{Com a globalização, o pluralismo e a democracia, nos meios de comunicação, dependem da expressão da diversidade cultural}

latino-americana

\section{UM MAPA DE PERGUNTAS}

A questão do pluralismo se torna crucial na hora de pensar a democracia e imaginar sua configuração neste fim de século. Afinal, de que estamos falando quando falamos de pluralismo? Do aprofundamento da democracia ou de um artifício neoliberal? De uma questão grave que diz respeito a problemas de estrutura da comunicação, que tanto pode resultar no reconhecimento entre os povos, as etnias e as raças, as idades e os sexos, quanto na flagrante desigualdade do acesso aos meios, de que ainda padecem tanto as maiorias como a maioria das minorias? Ou das leviandades de uma comunicação aliviada, devido à tecnologia, do peso dos conflitos e da obscuridade dos atores sociais, num processo no qual se liberam as diferenças e, sem necessidade de encontrar-se, todos comunicam e dela não poucos esperam, inclusive, a saída para a crise social e política?

Paradoxo: na década de 80 , uma das poucas indústrias que cresceram na América Latina, a única, inclusive, em que se fizeram grandes investimentos, foi a de comunicação. O número de estações de emissoras de televisão passou de 400 para cerca de 1.500 . Brasil e México adquiriram satélite próprio, as empresas de informação de rádio e de televisão abriram conexões mundiais via satélite. Até nos países mais pobres da região as cidades se encheram de antenas parabólicas e se implantaram redes de cabo. Os canais regionais de televisão apareceram e, de quase zero nos anos 70, passou-se a dez milhões de videocassetes em 1989 e a 12 mil videolocadoras com uma porcentagem média de 340 milhões de fitas alugadas por ano $^{2}$. Durante esses mesmos anos - segundo as insuspeitas cifras do Diretor do Banco Mundial para a América Latina - apareceram 60 milhões de novos pobres e a região

O AUTOR
Jesús Martín-Barbero
Assessor do Instituto de Estudos sobre Culturas
em Comunicação da Universidade Nacional,
Colômbia. Autor, entre outros, de De los medios
a las mediaciones.

1. Originalmente publicado em espanhol na revista DIA-LOGOS DE LA COMUNICACIÓN. Lima: Felafacs, n.40, set./1994. p. $72-79$.

2. GETINO, O. Introdución al espacio audiovisual latinoamericano. Buenos Aires: INC, 1990. Ver também: ALFONZO. A. Televisión de servicio público y televisión lucrativa en América Latina. Caracas: Doc. Ministério de Cultura, 1990. 
converteu-se na única do mundo na qual a distribuição da renda piorou ${ }^{3}$, ao mesmo tempo em que a participação latino-americana no Comércio Exterior da Comunidade Européia caiu mais de $30 \%{ }^{4}$.

A questão do pluralismo se converte em um enclave de paradoxos e desafios para a comunicação: o que ali está em jogo são apenas problemas de expressão - um pouco mais de espaço na imprensa, ou de tempo no rádio e na televisão para as minorias ou para os radicais - ou os problemas são de outro calibre e espessura tanto de uma perspectiva filosófica quanto política? Ou será que as questões de fundo, de estrutura e as dimensões sociais da democracia tornaramse anacrônicas para os desconcertados habitantes destes tempos e destes países emaranhados entre a dívida e a dúvida?

Tanto na Europa como nos Estados Unidos, não são poucos nem de pouca monta os pensadores que afirmam que a liberação das diferenças é resultado da ação dos meios massivos. Explicitando o que outros intelectuais sentem pudor de expressar, G. Vattimo afirma: "Os meios têm sido determinantes para o vir a dar-se conta da dissolução dos pontos de vista centrais, daqueles que J. F. Lyotard chama os grandes relatos, (...). Apesar de todo o esforço por parte dos monopólios e das grandes centrais capitalistas, o rádio, a televisão e os periódicos se converteram em componentes de uma explosão e multiplicação generalizada de Weltanschaungen: de visões do mundo"s. Deriva daí uma leitura muito particular que Vattimo faz de Walter Benjamin, segundo a qual os meios estariam na base da nova sensibilidade, do aparelho sensitivo pós-moder- no: aquela pluralização que dissolve os pontos de vista unitários e faz emergir de modo irrefreável a palavra das minorias de todo tipo, em todo o mundo.

\section{MEIOS DE COMUNICAÇÃO: DIVERSIDADE OU FRAGMENTAÇÃO?}

Seria fechar os olhos negar o esboroamento que hoje sofrem no mundo inteiro as visões unitárias da História e as concepções totalitárias. É mesmo impossível desconhecer que nas sociedades latino-americanas os meios, ao possibilitarem o acesso a outras visões de mundo e a outros costumes, contribuíram para arrefecer os sectarismos políticos e religiosos, relaxaram os talantes (arbítrios) repressivos e desarmaram as tendências autoritárias.

Mas os novos ventos de fanatismo e a propagação do fundamentalismo e do racismo não têm nada a ver com os meios de comunicação? Não há nisso - na massa de seus discursos e suas imagens - uma forte cumplicidade com esquematismos e maniqueísmos, com exaltações da força e da violência, que alimentam secreta e lentamente velhas e novas modalidades de intolerância e de integrismo?

Cenário, expressivo como nenhum outro, das contradições desta época, os meios nos expõem cotidianamente à diversidade dos gostos e das razões, à diferença, mas também à indiferença; à crescente integração do heterogêneo das raças, das etnias,

3. REVISTA CAMBIO 16 - COLÔMBIA. Bogotá, 18 de octubre, 1993.

4. FERRER, A. El reencuentro de dos mundos en Iberoamérica, una comunidad. El País. Madrid, 1991. Ver também: RONCAGLIOLO, R. Europa 1993: expectativas y riesgos para América Latina. Telos. Madrid, n.23, 1990.

5. VATTIMO, G. La sociedad transparente. Barcelona: [s.n.], 1990. p.78-79. 
dos povos e dos sexos no sistema de diferenças com o qual, segundo Baudrillard, o Ocidente conjura e neutraliza, funcionaliza os outros: "enquanto a diferença prolifera ao infinito na moda, nos costumes, na cultura, a alteridade dura, a da raça, da loucura, da miséria, terminou ou se converteu em um produto escasso"6. Como se apenas submetidas ao "esquema estrutural de diferenças" que o Ocidente propõe, nos fosse possível relacionar-nos com as outras culturas.

Não constituem os meios de comunicação um dos dispositivos mais eficazes desse esquema, utilizando-se dos procedimentos mais díspares? Eles buscam nas outras culturas o que mais se parece com a nossa e, para isso, silenciam ou enfraquecem os traços mais conflitivamente heterogêneos e desafiantes. Para tanto não haverá outro remédio senão estilizar e banalizar, isto é, simplificar o outro, ou melhor, descomplexizá-lo, torná-lo assimilável sem necessidade de decifrá-lo.

Não é com imagens baratas e esquemáticas dos indígenas, dos negros, dos subdesenvolvidos, dos primitivos que a imensa maioria dos discursos dos meios de comunicação - especialmente da televisão - nos aproximam dos outros? E de forma parecida funciona o mecanismo de distanciamento: $\mathrm{o}$ outro torna-se exótico, é folclorizado em um movimento de afirmação da heterogeneidade que ao mesmo tempo que o torna interessante o exclui do nosso universo, negando-lhe a capacidade de interpelar-nos e de questionar-nos?

Mas que ninguém busque as razões desse esquema, que a partir dos meios neutraliza as diferenças, em alguma perversão da sensibilidade sobre a qual tão positivamente falava Vattimo. Sua racionalidade não é outra senão a do contraditório movimento de globalização e fragmentação que configura o espaço-mundo da economia e da cultura hoje.

Global é o espaço novo que o mercado e as tecnologias produzem e do qual necessitam. Como ocorreu com o espaço nação a partir do fim do século XVII na Europa, agora é o espaço-mundo ${ }^{8}$ que se constitui em horizonte do fluxo econômico e informacional que tem como eixo a empresa, como chave a relação de interdependência e como veículo e sustentação a trama tecnológica da comunicação.

Na globalização, o que conduz o processo é o mercado. É ele que, agora, regula as relações entre os povos, as nações e as culturas, que institui os modelos de comunicação e dinamiza as redes. $O$ que está significando para o pluralismo o processo de globalização?

A forma mais plena de combater a exclusão e a segregação ou a dissolução de qualquer outro tipo de espaço; a expansão do não-lugar, esse mundo de passageiros e clientes no qual se está sempre e não se está nunca em casa $^{9}$, no qual a abolição das distâncias e o apagamento da memória produzem não apenas a confusão das línguas mas também o auge da insignificância?

Mais que oposto, complementar da globalização, o mundo vive um processo de expansão da fragmentação em todos os níveis e em todos os planos: do esboroamento das nações à proliferação das seitas, da re-

6. BAUDRILLARD, J. La transparencia del mal. Barcelona: [s.n.], 1991. p. 134.

7. Sobre a diferença excludente: SODRÉ, Muniz. A verdade seduzida. Rio de Janeiro: Codecri, 1983. p.42.

8. Ver a esse propósito: MATTELART. Armand. Comunicação mundo: história das idéias e das estratégias. 2.ed. Petrópolis: Vozes, 1996. 320p.

9. AUGÉ, M. Los no-lugares: espacios de anonimato. Barcelona: [s.n.], 1993. p.110. 
valorização do local à decomposição do social. E outra vez se impõe a pergunta: o crescimento da consciência da diversidade não está desembocando na relativização de toda certeza e na negação de qualquer tipo de comunidade e ainda de sociabilidade? ${ }^{10}$. E o desenraizamento que supõe ou produz essa fragmentação - no âmbito dos territórios ou dos valores - não estará na base dos novos integrismos e fundamentalismos?

O elogio da diversidade fala, por sua vez, de uma nova sensibilidade da nossa sociedade em relação ao plural, de uma nova percepção do relativo e precário das ideologias e dos projetos de libertação, mas fala também da vertigem do ecletismo que da estética à política fazem com que tudo tenha o mesmo valor.

Confusão a cuja sombra os mercadores fazem seus negócios, fazendo-nos crer, por exemplo, que a diversidade em televisão equivale à quantidade de canais. Desse modo, quantidade acaba com a qualidade e não oferece senão o simulacro oco da pluralidade.

Globalização e fragmentação complementam-se no âmbito do mercado - a descentralização das decisões na empresa, a segmentação dos públicos e das audiências dos meios - mas se contrapõem ao das sociedades e das culturas.

Nada mais eloqüente a esse respeito que a contradição que experimentam muitas pessoas progressistas e bem-pensantes dos países ricos quando o Terceiro Mundo se torna vizinho de bairro ou competidor na hora de buscar trabalho. Como se, ao caírem as fronteiras, que durante séculos demarcaram os diversos mundos, as distintas ideolo- gias políticas, os diferentes universos culturais - por ação conjunta da lógica econômica, da dinâmica tecnológica e da pressão migratória - tivessem colocado a descoberto as contradições do discurso universalista ${ }^{11}$, do qual o Ocidente sempre se sentiu tão orgulhoso.

Então, cada qual - cada país ou comunidade de países, cada grupo social e até cada indivíduo - necessitará afastar a ameaça que significa a proximidade do outro, dos outros em todas as suas formas e figuras, refazendo a exclusão agora já não sob a forma de fronteiras - que seria um obstáculo ao fluxo das mercadorias e das informações - e sim de distâncias que voltem a pôr cada qual em seu lugar.

\section{HETEROGENEIDADE E DEMOCRACIA}

\begin{abstract}
"Poderia narrar-se a história da América Latina como uma contínua e recíproca 'ocupação de terreno'. Não há uma demarcação estável, reconhecida por todos. Nenhuma fronteira física e nenhum limite social outorgam segurança. Assim nasce e se interioriza, de geração em geração, um medo ancestral do invasor, do outro, do diferente, venha de cima ou venha de baixo" 12 .
\end{abstract}

Ali onde o ordenamento coletivo é precário uma vez que idealizado como algo preconstituído ontologicamente e não cons-

10. Sobre a dissolução da sociedade por um "diferencialismo absoluto": TOURAINE. A. Les postmodernismes. In: Critique de la modernité. Paris: Fayard, parte 2, cap.3, 1992.

11. ENZENSBERGER. H. M. Cultura contra la violencia. Humboldt. Bonn: [s.n.], n. $108,1993$.

12. LECHNER, N. Los patios interiores de la democracia. Santiago: FLACSO, 1988. p.99. 
truído política e cotidianamente, a pluralidade é percebida pelos cidadãos como desagregação e ruptura da ordem, a diferença contém sempre algo de rebelião e a heterogeneidade é sentida como fonte de contaminação e deformação das purezas culturais.

$\mathrm{O}$ autoritarismo na América Latina não pode ser compreendido apenas como uma tendência perversa de seus militares ou de seus políticos, ele responde à precariedade da sociedade civil e à complexidade das mestiçagens que contém. Daí a tendência para fazer do Estado-Nação a figura que se opõe de forma vertical e centralista às debilidades da sociedade e às forças da dispersão. Definido pelos populismos em termos do telúrico e do racial, do autêntico e do ancestral, o nacional não tem história ou, quando muito, uma história legendária de heróis e arquétipos. Isso significou a permanente substituição do povo pelo Estado e o protagonismo deste em detrimento da sociedade civil ${ }^{13}$.

A preservação da identidade nacional se confunde com a preservação do Estado e a defesa dos interesses nacionais posta acima das demandas sociais acabará justificando - como aconteceu nos anos 70 com a doutrina da segurança nacional - a suspensão/supressão da democracia.

Os países da América Latina têm uma larga experiência dessa inversão de sentido em que a identidade nacional é posta a serviço de um chauvinismo que racionaliza e oculta a crise do Estado-Nação como sujei- to capaz de fazer real aquela unidade que articularia as demandas e representaria os diversos interesses que sua idéia deseja, ambiciona, cobiça. Crise disfarçada pelos populismos e desenvolvimentismos, mas operante na medida em que as nações se fizeram não assumindo as diferenças e sim subordinando-as a um Estado que, mais que integrar, soube centralizar.

Como afirma Hilda Sábato, até há bem pouco tempo o debate político e cultural se movia entre "essências nacionais e identidades de classe" 14 . Foi só durante a crise dos anos 70 que se colocou em questão o modelo que exigia a dissolução das identidades regionais, étnicas ou setoriais como condição indispensável para a construção da nação. A possibilidade de pensar a sociedade nacional como um ser plural se acha ligada à emergência de movimentos sociais nos quais começa a ser superada uma concepção puramente tática da democracia - como mero estratagema para a tomada do poder - $\mathrm{e}$ uma concepção que deixava de compreender o proletariado como o único ator da transformação.

São movimentos sociais que revalorizam as mediações da sociedade civil e o sentido social dos conflitos para além de sua formulação política ${ }^{15}$, fazendo possível a emergência, como sujeitos sociais, das etnias e das regiões, dos sexos e das gerações.

Foi então que o pluralismo, que tinha vivido enclausurado nos círculos intelectuais ou restrito a curtos momentos de hegemonia liberal, desenvolveu-se, soltou-se nestes países, tornando possível a convi-

13. FLIFISCH. A. et al. Problemas de la democracia y la política democrática en América Latina. Santiago: FLACSO. 1984: LECHNER, N. (ed.) Estado y política en América Latina. México: Siglo XXI, 1988.

14. SÁBATO, H. Pluralismo y nación. Punto de Vista. Buenos Aires, n.34, 1989. p.2. Ver também: SCHMUCLER, H. Los rostros familares del totalitarismo: nación, nacionalismo y pluralidad. Punto de Vista. Buenos Aires, n.33, 1988.

15. Um debate pioneiro na América Latina sobre a nova cultura política e comunicação: CASULLO, N. (coord.). Comunicación: la democracia difícil. Buenos Aires: ILET, 1985. 
vência do catolicismo com as religiões afroamericanas; a presença crescente das seitas protestantes e uma secularização progressiva dos costumes e das idéias. Isso, por sua vez, tornará visível e aceitável uma concepção nova de identidade, já não mais construída de essências e raízes e sim de relações e interações. Assim vê Carlos Monsivais a nova identidade do mexicano: "O mexicano já não é um problema existencial e cultural, e apesar das infindáveis discussões, a identidade nacional não está em risco. É uma identidade mutante, enriquecida continuamente com a fala dos marginais, os aportes dos meios de comunicação, as renovações acadêmicas, as discussões ideológicas, a americanização, a resistência à ampliação da miséria, a qual se debilita ao reduzir-se a capacidade dos centros de ensino e ao institucionalizar-se a resignação ante a ausência de estímulos culturais"16.

Assim se vê a si mesmo um habitante da fronteira norte que assume, para definir-se, as múltiplas dinâmicas de desterritorialização e hibridização que o conformam: "quando me perguntam por minha nacionalidade ou identidade étnica não posso responder com uma palavra, pois minha 'identidade' já possui repertórios múltiplos: sou mexicano mas também sou chicano e latino-americano. Na fronteira me dizem chilango ou mexiquillo, na capital pocho ou norteño e na Europa suda$c a$. Os anglo-saxões me chamam de hispanic ou latino e os alemães me confundiram em mais de uma ocasião com turco ou italiano"17.
No que se refere à esfera política, ainda permanecem fortes mostras de fundamentalismo nas guerrilhas e de integrismo em esquerdas e direitas. Mas o pluralismo se manifesta em um esfriamento da luta política que começa a desarmar intransigências, a dessatanizar o adversário. Isso implica, por sua vez, uma destotalização da política, que não se constitui apenas em dessacralização dos princípios, mas também da sua própria concepção e do alcance do que nela se joga: seu âmbito, mais que o da confrontação pelo poder, começa a ser o da negociação e o da construção coletiva de uma ordem $^{18}$. Mesmo nesse âmbito ela já não pode pretendê-lo integralmente ou atravessálo todo: a política reencontrou ultimamente os limites que a diferenciam da ética e da cultura.

Mas esta desdramatização da políti-
ca se produz na América Latina ao mes-
mo tempo em que o contágio do Norte
produz sua espetacularização. Digamos
firmemente, para fazer frente aos novos
apocalípticos, que não acreditamos que a
relação da política com os meios, em es-
pecial com a televisão, seja o lugar onde
se gesta ou toma forma a dissolução do
político.

A espetacularização não é o efeito do meio sobre a mensagem e sim a própria forma do discurso da política em um tempo no qual, como afirma Richeri, "progressivamente separados do tecido social de referência, os partidos se reduzem a sujeitos

16. MONSIVAIS, C. De la cultura mexicana en vísperas del tratado do libre comercio. México: Nueva Imagen, 1992. p. 192.

17. Citado em: CANCLINI, N. García. Culturas híbridas: para entrar y salir de la modernidad. México: Grijalbo, 1990. p. 302 .

18. Duas recompilações de textos chaves sobre o tema na América Latina: LECHNER, N. (comp.) Cultura política y democratización. Santiago: FLACSO/CL.ACSO/ICI, 1987. SCHMUCLER, H.; MATA, Maria Cristina (coord.) Política y comunicación: hay un lugar para la política en la cultura massmediática? Córdoba: Catálogos, 1992. 
de um evento espetacular como qualquer outro" 19 . Sem esquecer a este respeito que a política se relaciona ao espetáculo massmediático a partir do que ela tem, e teve sempre, de ritualidade e de teatralidade. Isso nos obriga a retomar o eixo das relações entre democracia e comunicação ${ }^{20}$.

\section{O PLURALISMO NOS MEIOS}

"Apesar das grandes diferenças nas filosofias políticas que as motivaram, todas as reformas guardam relação, de um modo ou de outro, com a introdução, nos meios de comunicação, de funções de serviço público, de preservação das tradições culturais e criativas e da formulação de políticas que beneficiassem os numerosos setores desfavorecidos da sociedade. À sua maneira também guardavam relação com projetos de estruturas democráticas e disposições de gestão que fossem representativas, participativas e operativas" 21 . Assim caracteriza Elizabeth Fox o projeto de democratização que as políticas nacionais de comunicação encarnavam e pelas quais se lutou na América Latina desde os anos 70 .

Perseguidas pelos regimes ditatoriais que governavam mais da metade dos países nesses anos, e frustradas na hora de aplicálas naqueles outros países que as acolheram, essas políticas expressavam os ideais e os limites da democracia comunicativa desse tempo. Pois, se expressavam o desejo de fortalecimento da esfera pública contra o poder incontrolado dos interesses privados, estavam, sem dúvida, embasadas na velha e persistente confusão do público com o estatal: mais que uma questão referida à forma da sociedade - da qual fazem parte o Estado e o mercado, partidos e movimentos, instituições e vida cotidiana - a comunicação que essas políticas recortaram e focalizaram se esgotou no âmbito da possibilidade de democratização unicamente a partir do Estado, a partir da institucionalidade estatal.

A outra preocupação central que orientava essas políticas era o conteúdo nacional dos meios, com cuja regulamentação se buscava fazer frente à erosão das culturas nacionais e à penetração descarada ou disfarçada do imperialismo cultural que vinha do Norte. Mas a idéia do nacional que essas políticas sustentavam deixava fora a diferença.

Visto através da nação, o povo era uno e indivisível, e a sociedade "um sujeito sem texturas nem articulações internas, de uma homogeneidade tão grande quanto a que acusávamos nossos inimigos de querer converter-nos"22. Não será estranho então que, enquanto no pensamento dos pesquisadores e dos analistas políticos a reformulação do modelo dos meios apontava para garantir os direitos das maiorias, os governos ressemantizaram essas propostas em termos de ampliação de sua própria presença no espaço massmediático ou de alargamento de sua capacidade de intervenção ${ }^{23}$. Não foi só a cerrada oposição do setor privado e seus interesses mercantis os que frustraram as re-

19. RICHERI, G. Crisis de la sociedad y crisis de la televisión. Contratexto. Lima, n.4, 1989. p.144.

20. Uma visão de conjunto sobre essas relações: BARBERO, Jesús Martín. El tejido comunicativo de la democracia. Telos. Madrid, n.27, 1991.

21. FOX, E. (ed.) Medios de la comunicación y política en América Latina. Barcelona: Gustavo Gili, 1989 . p.40.

22. CALETTI, S. Comunicación, cambio social y democracia: ocho años después. In: ESTEINOU, J. (ed.) Comunicación y democracia. México: CONEIC, 1992.

23. Sobre essa intervenção: FOX. E. op. cit., p.35-52 e 78-90. 
formas, elas estavam minadas de dentro pelo déficit da sociedade civil e da pluralidade que continham.

Se nos anos 70 o sujeito social era uno e democratizar a comunicação consistia em colocá-la a seu serviço, nos anos 80 a heterogeneidade do social vai começar a permear as propostas de comunicação, desestatizando-as e diversificando-as. $\mathrm{A}$ isso se adiantou pioneiramente o rádio. Revalorizado em sua oralidade - em sua continuidade e cumplicidade com as matrizes culturais do oral -, ligou-se ao surgimento de movimentos populares, como no caso das rádios mineiras bolivianas ${ }^{24}$, num processo que envolveu com intensidade cada vez maior os grupos indígenas, comunidades de bairro, sindicatos, instituições universitárias 25 .

Como nenhum outro meio, o rádio foise fazendo plural, a voz da diversidade do campo e da cidade, da Capital e do Interior, abrindo-se à heterogeneidade dos territórios e das regiões, às suas desigualdades e suas diferenças.

Também na televisão emerge uma certa pluralidade, especialmente a que os canais regionais tornam possível. Vistos a princípio com receio pelos poderes centrais, pelo que significam de descentralização e dispersão do poder, e pelas empresas nacionais diante da competição estabelecida, o processo mostra, sem dúvida, que a radicalização das políticas de privatização ameaça seriamente transformar a regionalização televisiva em estratégia de expansão e consolidação de grupos nacionais e transnacionais.

Ainda que atravessada pelas ambigüidades de sua relação com a administração estatal e pelas distorções que as pressões de mercado introduzem, a televisão regional significa, na América Latina ${ }^{26}$, para uma multidão de comunidades locais e de grupos sociais, a primeira oportunidade de construir sua própria imagem.

Depois de tanto tempo de haverem sido negadas, excluídas da televisão impropriamente denominada nacional as gentes das regiões queriam ver-se, olhar-se em suas cores e suas paisagens, em suas personagens e suas festas. Ao fim e ao cabo, não é a partir da pomposa e retórica identidade nacional que se vai poder enfrentar a globalização transnacional e sim a partir do que permanece em cada país, de culturalmente mais vivo.

A cultura regional ou local significa, então, não o exótico e o folclorizado - a diferença enclausurada e excludente - e sim o que culturalmente é capaz de expor-se ao outro, de intercambiar com ele e recriar-se. É o que estão fazendo as televisões regionais quando, para lutarem contra suas próprias inércias e estereótipos, refazem a memória e recolocam a noção mesma de cultura para que nela caibam as obras e as vi-

24. Um balanço atualizado dessa experiência: BELTRÁN, L. R.; REYES. J. Radio popular en Bolivia: la lucha de obreros y campesinos para democratizar la comunicación. Dia-logos de la comunicación. Lima, n.35, 1993, p.14-32.

25. Sobre o assunto mais informações em: MATA. Maria Cri.tina. Cuando la comunicación puede ser sentida como propia: una experiencia de radio popular. In: Comunicación y cul uras populares. México: Gustavo Gili. 1987. p.216-230. ROMO, C. La otra radio. México: Fund. Manuel Buendía, 1990. TEALDO. A. R. (ed.) Radio y democracia en América Latina. Lima: IPAL, 1989. ALFARO, R. M. et al. Cultura de masas y cultura popular en la radio peruana. Lima: Calandria/Tarea, 1990.

26. FESTA. R.; SANTORO, L. F. A terceira idade da TV: o local e o internacional. In: Rede Imaginária. São Paulo: Cia. das Letras, 1991. PORTALES, D. La integración televisiva desde lo global y lo local. In: La integración cultural latinoamericana. México: Felafacs, 1992. FOX. E.; ANZOLA. P. Politica y televisión regional en Colombia. In: FOX, E. op. cit., p.78-90. 
das, o letrado e o oral, o teatro e a cozinha, as diferentes religiões e as diferentes sexualidades.

Finalmente, o vídeo independente está abrindo outro espaço de pluralismo comunicativo na América Latina e, nos últimos anos, tem adquirido uma importância cultural e política formidável. Com mais de quinhentos grupos de produção popular e alternativa, e com várias redes de intercâmbio entre produtores de todo o continente - como a rede de vídeo do IPAL em Lima ${ }^{27}$, a Rede de vídeo pastoral em Quito e a Videoteca do Sul em Nova York - o vídeo está perdendo o seu complexo de inferioridade estética frente ao cinema e superando as tentações marginais que o opunham de forma maniqueísta à televisão. Funcionando em circuitos paralelos ou abrindo caminhos nas brechas dos circuitos do mercado, o vídeo independente está fazendo chegar ao mundo cultural uma heterogeneidade insuspeitada de atores sociais e uma riqueza de temas e narrativas através das quais emergem e se expressam mudanças de fundo na cultura política dos setores mais jovens.
Frente ao ardiloso pluralismo dos pós-modernos, que confundem a diversidade com a fragmentação e o fundamentalismo dos nacionalistas étnicos que transformam a identidade em intolerância, comunicação plural significa na América Latina o desafio de assumir a heterogeneidade como um valor articulável à construção de um novo tecido do coletivo.

Enquanto nos países centrais o elogio da diferença tende a significar dissolução da sociabilidade, na América Latina, como afirma Lechner, "a heterogeneidade só produzirá dinâmica social ligada a alguma noção de comunidade" ${ }^{28}$. Certamente não à idéia de comunidade resgatada de algum idealizado passado e sim àquela a partir da qual nos é possível recriar hoje as formas de convivência e deliberação cidadã, sem reassumir a moralização dos princípios ou a absolutização das ideologias, refazendo melhor as identidades e os modos de simbolizar os conflitos e os pactos a partir da opacidade e da complexidade das hibridizações e das reapropriações.

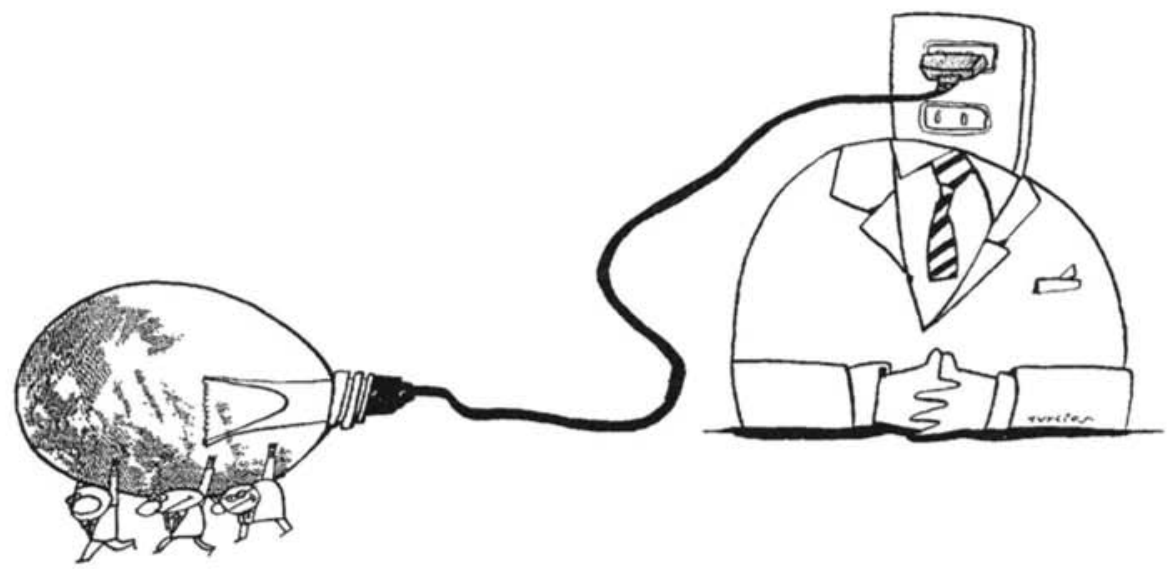

27. GONZÁLEZ. M. (ed.) Video, tecnología y comunicación popular. Lima: IPAL/CIC, 1989.

28. LECHNER, N. La democratización en el contexto de una cultura postmoderna. In: mocratización. Santiago: FLACSO/CLACSO, 1987. Cultura política e de- 
Resumo: $\mathrm{O}$ autor discute o pluralismo e a democracia na comunicação. Defende a necessidade de expressão da diversidade cultural latino-americana. Polemiza com a concepçāo de Estado-Nação, enquanto discurso totalitário versus a diversidade comunitária e sua expressão na globalização.

Palavras-chave: comunicaçāo, pluralismo, sociabilidade, diversidade cultural, globalização
Abstract: The author discusses pluralism in communication based on the possibility that Latin-American cultural diversity may establish itself as a community, and express itself elsewhere. He also opposes the idea of a State-Nation as a totalitary discourse versus community diversity, and points out the need for expressing itself in the process of globalization.

Key-words: communication, pluralism, globalization, sociability, cultural diversity 